ISSN: 1979-7362

\title{
Rancang Bangun Sistem Kendali Kecepatan Putar Motor DC menggunakan PID Controller pada Mesin Pengaduk
}

\author{
Kasmira $^{1}$, Abdul Waris ${ }^{1}$, Muhammad Tahir sapsal ${ }^{1}$ \\ 1)Program Studi Teknik Pertanian, Universitas Hasanuddin Makassar
}

\begin{abstract}
ABSTRAK
Kegiatan pengadukan bahan-bahan pertanian menjadi berbagai macam produk pangan ataupun non pangan membutuhkan mesin pengaduk. Mesin pengaduk dalam penelitian ini memiliki masalah saat digunakan yaitu bahan yang diaduk melumpah dari wadah, suara yang dihasilkan berisik dan motor cepat panas. Penelitian ini bertujuan untuk menghasilkan sistem kendali yang baik pada mesin pengaduk agar dapat meningkatkan kinerja dari mesin pengaduk. Metode yang dilakukan yaitu perancangan sistem perangkat keras dan perangkat lunak. Sistem perangkat keras menggunakan komponen mikrokontroler, Solid State Relay (driver motor), Motor DC (aktuator), rotary encoder (sensor) dan power supplay (sumber tegangan) sedangkan sistem perangkat lunak berisi algoritma bahasa program kendali PID. Prinsip kerja sistem yaitu lup tertutup dimana kecepatan motor akan terbaca oleh sensor dan diinformasikan ke mikrokontroler untuk membandingkan dengan kecepatan yang diinginkan, kemudian memperbaiki kesalahan yang terjadi. Berdasarkan hasil tuning dengan menggunakan metoda internal control (MIC) diperoleh konstanta PID sebesar Kp: 0.259, Ki:5.647 dan Kd: 0.200. Nilai konstanta yang diperoleh sudah dapat memberikan kestabilan pada berbagai kecepatan $(62,130,190$ dan $252 \mathrm{rpm})$. Pengujian kecepatan motor DC pada mesin pengaduk dengan mengunakan beban yaitu adonan roti dan kedelai menghasilkan kecepatan yang dapat mengikuti set point (kecepatan yang diinginkan) dan respon sistem menunjukkan settling time yang pendek, overshoot bernilai 0 dan nilai error steady state yang masih berada pada batas toleransi yaitu $2 \%$ atau $5 \%$.
\end{abstract}

Keyword: Kecepatan, PID dan Kestabilan

\section{PENDAHULUAN}

\section{Latar Belakang}

Kegiatan pascapanen untuk mengolah hasil pertanian menjadi berbagai macam produk sangat beragam, seperti pengeringan, penepungan, fermentasi, pengadukan dan lain - lain. Kegiatan pengadukan sebagai salah satu proses pascapanen biasanya dilakukan pada berbagai pencampuran bahan, pembuatan kue tradisional, pembuatan tepung makanan bayi, roti, kue, virgin coconut oil dan sebagainya. Untuk mendukung kegiatan pengadukan dibutuhkan sarana penunjang yaitu mesin pengaduk (mixing). Mesin pengaduk saat ini sangat dibutuhkan bukan hanya untuk industri makanan dan minuman, tetapi juga mencakup industriindustri kimia.
Salah satu UMKM di Kabupaten Sinjai memiliki mesin pengaduk untuk membuat berbagai macam produk misalnya minyak kelapa murni (VCO), sabun dan produk lainnya. Mesin pengaduk yang digunakan merupakan hasil rancangan dari UMKM tersebut. Menurut pak Rudi yang merupakan ketua dari UMKM tersebut, mesin pengaduk yang digunakan memiliki masalah saat digunakan yaitu ketika proses pengadukan berlangsung bahan yang diaduk melumpah dari wadah (walaupun telah diberi penutup), suara mesin yang berisik dan kondisi motor yang cepat panas.

Mesin pengaduk dalam penelitian ini, motor yang digunakan memiliki kecepatan putar $2850 \mathrm{rpm}$. Jenis motor yang digunakannya merupakan motor yang biasa untuk pompa air. Ketika mesin dihidupkan motor akan langsung bekerja 
pada kecepatan maksimal yaitu $2850 \mathrm{rpm}$. Kecepatan tersebut akan membuat bahan yang diaduk jelas melumpah, karena kecepatan yang tinggi, sedangkan untuk melakukan pengadukan terhadap bahan cair seperti santan hanya diperlukan kecepatan 100 - 1750 rpm.

Dalam proses pengadukan, pengaturan kecepatan putar motor perlu untuk dilakukan karena setiap bahan memiliki karakteristik yang berbeda - beda. Putaran motor sebaiknya disesuaikan dengan jenis bahan yang diaduk. Hal ini bertujuan untuk meningkatkan kualitas pengadukan atau pencampuran menjadi lebih baik dan penggunaan energi listrik dapat lebih hemat. Pengaturan kecepatan dapat dilakukan dengan menggunakan sistem kendali terhadap kecepatan putar motor. Ada berbagai cara dalam mengatur kecepatan motor, salah satu cara yang mudah untuk dilakukan yaitu pengaturan frekuensi motor dengan menggunakan PWM. Sistem kendali akan memberikan kestabilan pada kecepatan motor yang diinginkan. Pengadukan dengan kecepatan rendah yaitu 100 rpm digunakan untuk minyak kental, lumpur dimana terdapat serat atau pada cairan yang dapat menimbulkan busa. Pada kecepatan sedang yaitu $1150 \mathrm{rpm}$ digunakan untuk larutan sirup kental, dan minyak pernis sedangkan kecepatan tinggi yang berkisar pada 1750 rpm umumnya untuk fluida dengan viskositas yang rendah misalnya air (Hermawan, 2015).

Berkaitan dengan faktor kecepatan pengadukan, penelitian yang dilakukan oleh Rahman dkk, menyimpulkan bahwa pada kecepatan $64 \mathrm{rpm}$ pembuatan krupuk pansit sangat baik karena air yang dituangkan pada bahan adonan dapat mengalir lebih lambat sehinga membuat adonan tercampur lebih merata. Penelitian yang dilakukan Priyati (2016) menunjukkan bahwa kecepatan pengadukan $200 \mathrm{rpm}$ lebih baik dalam pembentukan gluten pada adonan dibandingkan dengan kecepatan rendah. Sedangkan pada penelitian yang dilakukan oleh Bregas (2010) pengadukan dengan mengunakan kecepatan putar $300 \mathrm{rpm}$ dan waktu pengadukan optimal 70 menit menghasilkan fraksi minyak VCO yang lebih banyak dibandingkan dengan menggunakan kecepatan putar yang lain.

Sistem kendali yang dapat diterapkan yaitu sistem kendali PID. Sistem kendali PID merupakan sistem kendali yang banyak digunakan dalam industri-industri karena kehandalannya dalam mengontrol kecepatan motor. Pengendali ini memiliki kelebihan pengaturan kecepatan yang lebih halus dan stabil. Dalam pengontrolan kecepatan motor dengan menggunakan PID ini, pencarian parameter dilakukan dengan menggunakan metoda internal control (MIC), karena parameter-parameter PID yang di peroleh sudah dapat digunakan untuk berbagai macam variasi kecepatan tanpa harus melakukan proses tuning kembali. Dalam perancangan sistem perlu dilakukan pengaturan parameter $\mathrm{P}$, I dan $\mathrm{D}$ agar tanggapan keluaran sistem terhadap masukan sesuai dengan keinginan. Kendali PID membandingkan nilai yang terukur di $\mathrm{y}$ dengan nilai referensi yaitu nilai SP. Nilai ini kemudianakan digunakan untuk menghitung input proses yang baru. Input ini akan memcoba mengatur proses yang terukur agar kembali pada setting point yang diinginkan (Fathur, 2016).

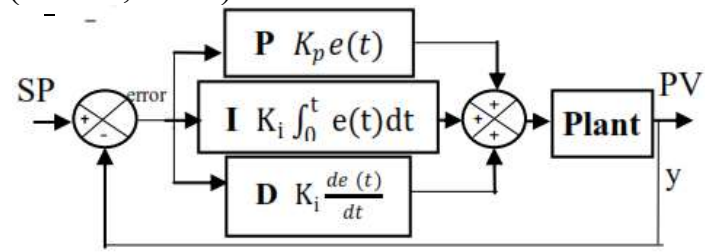

Gambar 3. Blok diagram pengendali PID

Secara umum sinyal error merupakan selisih antara set point dengan keluaran plant. Secara matematis dituliskan (Wisesa, 2014):

$\operatorname{error}(t)=S P(t)-P V(t)$

SP : Nilai masukan yang diinginkan

PV : nilai kecepatan yang sebenarnya.

Terbaca melalui sensor kecepatan

error : perhitungan dari SP-PV (nilai inibisanegatif bisa positif).

Secara umum sinyal kontrol dituliskan: 
$u(t)=K p\left(e[t]+K i \int e[t] d t+K d \frac{d e(t)}{d t}\right) \begin{aligned} & T_{d}=\frac{T \cdot d}{2 T+d} \\ & \text { Dimana: }\end{aligned}$

dengan:

$\mathrm{u}(\mathrm{t}) \quad=$ sinyal kontrol

$\mathrm{Kp}=$ konstanta proporsional

$\mathrm{Ki}=$ konstanta integral

$\mathrm{Kd} \quad=$ konstanta differensial

Dalam bentuk digital rumus diatas dituliskan sebagai berikut:

$u(n)=K p\left(e[n]+K i \sum e[n] T+\right.$

$\left.K d \frac{e[n]-e[n-1]}{T}\right)$

$\mathrm{u}[\mathrm{n}]$ : Sinyal kontrol. Dalam hal ini adalah nilai PWM (nilai OCR1)

e[n] : error ke-n (saat ini)

$\mathrm{T}$ : Time sampling

$\mathrm{e}[\mathrm{n}-1]$ : error sebelumnya

Penentuan konstanta - konstanta PID dapat dilakukan dengan proses tunning. Konstanta yang dibutuhkan dalam kontrol ini adalah $\mathrm{K}, \mathrm{T}$ dan $\mathrm{d}$. $\mathrm{K}$ merupakan perbandingan antara kecepatan motor terukur (rps) dan perintah pengendalian motor (pwm), T adalah waktu konstan (s) dan d adalah delay (s) (Sapsal, 2012).

Konstanta $\mathrm{T}$ dan d diperoleh dengan menjalankan motor dengan kecepatan maksimum, data kecepatan motor direkam setiap $5 \mathrm{~ms}$ dan motor dijalankan selama 1 detik. Hal ini diulang tiga kali. Data yang diperoleh kemudian diplotkan menggunakan model $g(t)=1-$ $e^{-\frac{K}{T}(t-d)}$ untuk $\mathrm{t}>\mathrm{d}$ dan $\mathrm{g}(\mathrm{t})=0$ untuk $\mathrm{t}<$ d. Konstanta $\mathrm{K}$ diperoleh dengan membandingkan nilai PWM dan kecepatan motor. Nilai $\mathrm{K}, \mathrm{T}$ dan $\mathrm{d}$ yang diperoleh. Digunakan untuk menentukan koefisien $\mathrm{Kp}$, Ti dan Td dengan Metoda Internal Control (MIC). Metode ini melakukan pengujian yang lebih baik dibandingkan dengan metoda Ziegler Nichols. Penentuan nilai $\mathrm{Kp}$, $\mathrm{Ti}$ dan $\mathrm{Td}$ dengan Metoda Internal Control (MIC), menggunakan persamaan (Sapsal, 2012):

$K_{p}=\frac{1}{K}\left[\frac{T+0.5 d}{T_{c}+0.5 d}\right]$

$T_{i}=T+0.5 d$
$\mathrm{K}$ : konstanta perbandigan antara kecepatan motor terukur (rps) dan perintah pengendali motor (pwm)

$\mathrm{T}$ : Waktu konstan atau time constant (s)

$\mathrm{d}$ : Delay atau dead time (s)

Tc : Waktu kontrol (s)

Respon transien sistem kontrol sering menunjukkan osilasi teredam sebelum mencapai keadaan tunak. Dalam menentukan karakteristik respon transien sistem kontrol terhadap masukan tangga satuan biasanya dicari parameter berikut (Ogata, 1995):

1. Waktu tunda (delay Time), $\mathrm{t}_{\mathrm{d}}$

2. Waktu naik (rise time), $\mathrm{t}_{\mathrm{r}}$

3. Waktu puncak (peak time) $\mathrm{t}_{\mathrm{p}}$

4. Lewatan maksimum (maximum overshoot), $\mathrm{Mp}$

5. Waktu penetapan (settling time), $\mathrm{t}_{\mathrm{s}}$

\section{Tujuan dan Manfaat}

Tujuan penelitian yaitu menghasilkan sistem kendali yang baik pada mesin pengaduk agar dapat meningkatkan kinerja dari mesin pengaduk UMKM. Sedangkan manfaat dari penelitian ini adalah untuk membantu masyarakat dalam pengadaan mesin-mesin yang memiliki kinerja yang baik dan memberikan informasi bagi perancang dalam mengontrol kecepatan motor mesin pengaduk dengan menggunakan kontrol PID pada mesin - mesin pertanian.

\section{BAHAN DAN METODE}

\section{Alat dan bahan}

Alat yang digunakan yaitu bor portabel, solder, jangka sorong, penghisap timah, cutter, gunting, mesin las dan laptop. Sedangkan bahan yang digunakan yaitu komponen elektronika, SSR DCtoDC, rotary encoder, heatsink, motor Dc, kabel, mikrokontroler ATMega 32, timah, mur dan baut. Bahan untukpengujian yaitu adoan roti dan 
kedelai. Dan untuk software digunakan CodeVision AVR 2.0.5.3, AVR-OspII, Serial Port to MSi 2011 dan mikrosoft Exel.

\section{Metode Perancangan}

Metode perancangan untuk menghasilkan sistem kendali pada mesin pengaduk dilakukan dengan menggunakan tahapan sebagai berikut:

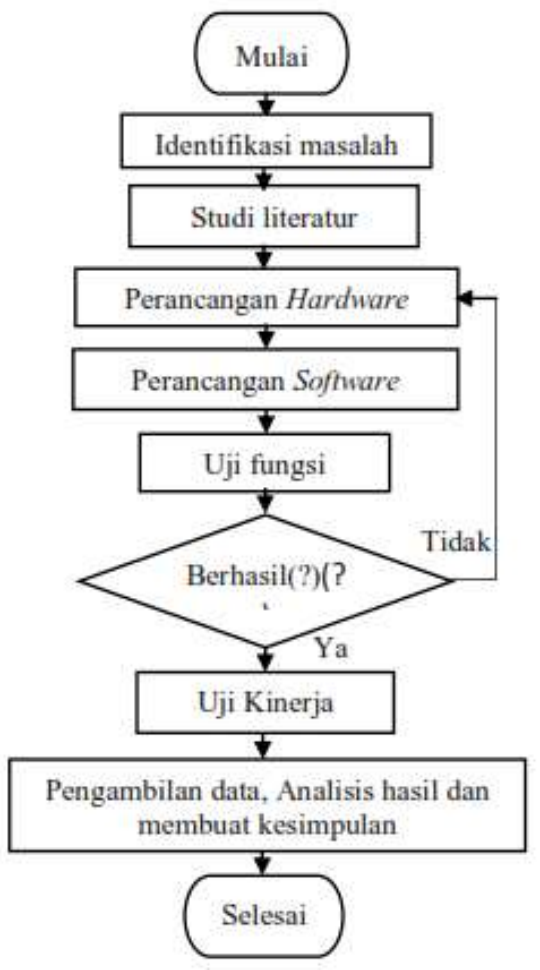

Gambar 1. Bagan alir proses penelitian

\section{Perancangan Sistem Kendali PID}

Tujuan dari perancangan sistem kedali adalah untuk mengatur kecepatan putar motor agar dapat mencapai set point sehingga motor dapat bekerja dengan berbagai variasi kecepatan putar. Perancangan sistem pengendali kecepatan motor pada mesin pengaduk digambarkan dalam blok diagram berikut ini:

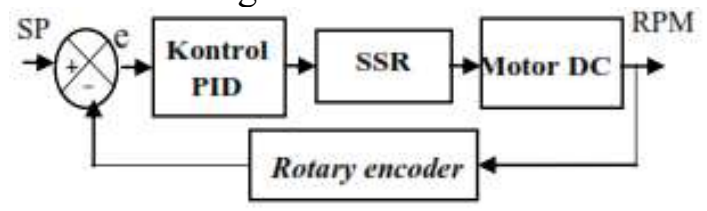

Gambar 2. Diagram blok sistem kendali PID
Berikut ini diagram alir perancangan sistem kendali PID:

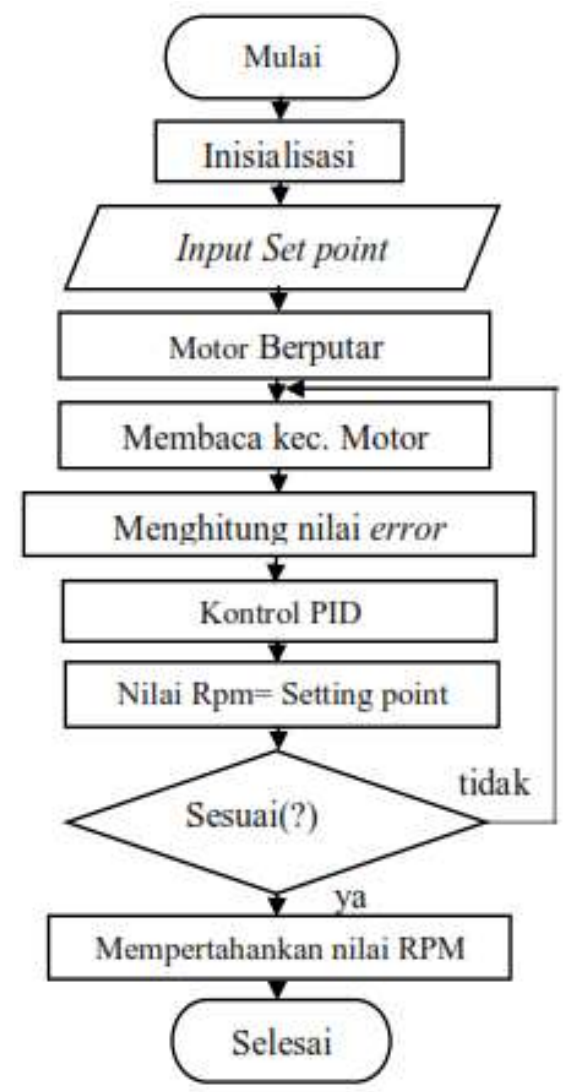

Gambar3. Bagan alir Sistem kendali PID

\section{Prosedur PencarianKonstanta PID}

Dalam kontrol PID konstantan yang diperlukan dalam sistem yaitu $\mathrm{K}, \mathrm{T}$ dan $\mathrm{d}$. Nilai K diperoleh dengan membandingkan nilai kecepatan (rps) dari motor dengan nilai PWM, T merupakan waktu konstan (s) sedangkan d merupakan waktu delay. Untuk mendapatkan nilai $\mathrm{T}$ dan $\mathrm{d}$ motor dijalankan dengan kecepatan maksimum dan dilakukan perekaman nilai kecepatan setiap $10 \mathrm{~ms}$ sebanyak 1000 kali dimana perekamanan diulang sebanyak 3 kali. Data tersebut kemudian diplotkan menggunakan model $g(t)=1-e^{\frac{K}{T}(t-d)}$ untuk $\mathrm{t}>\mathrm{d}$ dan $\mathrm{g}(\mathrm{t})=0$ untuk $\mathrm{t}<\mathrm{d}$. Nilai $\mathrm{K}, \mathrm{T}$ dan $\mathrm{d}$ yang telah didapatkan akan digunakan untuk menentukan nilai $\mathrm{Kp}$, Ti dan Td dengan menggunakan metode internal kontrol. 


\section{Prosedur Pengujian}

Pengujian bertujuan untuk mengetahui kinerja dari sistem kendali yang telah dibuat pada mesin pegaduk. Ada tiga jenis pengujian yang dilakukan yaitu

1. Uji fungsional sistem kendali

Uji fungsional dilakukan dengan membuat program untuk pengaturan kecepatan motor 0,20,40,60,80,60,40,20,0 dengan durasi perekaman data kecepatan setiap setpoint selama 10 detik dan dilakukan sebanyak 3 kali kemudian dirataratakan. Kriteria uji fungsional yaitu:

a. Kecepatan motor stabil pada set point yang diberikan.

b. Respon sistem tidak mengalami overshoot, settLing time berkisar 010 detik, offset 2\% atau 5\% (Ogata, 1997) dan error stady state yang kecil.

2. Uji kinerja mesin dengan sistem kendali Uji kinerja dengan menggunakan sistem kendali dilakukan dengan memasukkan algoritma program kendali yang telah dibuat kedalam mikrokontroler, kemudian menjalankan motor dengan memberikan beban kerja. Pengambilan data dilakukan pada setiap set point yaitu 20,40,60 dan 80 rps selama 30 detik sebanyak 3 kali kemudian dirataatankan. Kriteria uji kinerja dari mesin pengaduk yaitu:

a. Motor dapat berputar mengikuti setpoint yang diberikan selama proses pengadukan dengan torsi beban yang berbeda.

b. Menghasilkan kecepatan yang stabil.

3. Uji kinerja mesin tanpa sistem kendali

Pengujian tanpa kontrol yang dilakukan bertujuan untuk melihat kecepatan motor saat diberikan beban. Bahasa program yang digunakan berbeda dengan uji menggunakan kontrol. Pemberian nilai PWM didasarkan pada persamaan linearitas dari motor yaitu $y=2,6636 x$. Nilai y merupakan nilai PWM yang akan mengendalikan putaran motor, sedangkan nilai $\mathrm{x}$ merupakan rps saat motor berputar. Nilai rps nantinya akan di plotkan dengan nilai set point dan waktu untuk melihat respon transien motor dengan beban yang berbeda.

\section{Pengukuran Torsi Beban}

Pengukuran terhadap torsi bahan bertujuan untuk mengetahui torsi beban yang akan diaduk, dilakukan dengan cara mengukur gaya berat yang bekerja antara propeller denga bahan. Gaya berat didapatkan dengan cara menarik propeller dengan alat ukur massa secara melingkar mengikuti putaran propeller oleh motor. Selain mengukur gaya berat (w), dilakukan pula pengukuran panjang lengan. Panjang lengan (d) merupakan panjang dari propoller secara vertikal yang diukur dari titik tengah percabangan hingga ujung percabangan. Nilai tersebut kemudian dimasukkan kedalam persamaan (8)

$$
T=w \times d
$$

Dimana,

$T=$ torsi beban $(\mathrm{Nm})$

$w=$ berat beban atau $w=m \cdot g\left(\mathrm{kgm} / \mathrm{s}^{2}\right)$

$\mathrm{d}=$ panjang lengan (meter)

\section{HASIL DAN PEMBAHASAN}

Berdasarkan penelitian yang telah dilakukan Gambar 7 memperlihatkan hasil rangcangan sistem kendali PID yang telah dibuat.

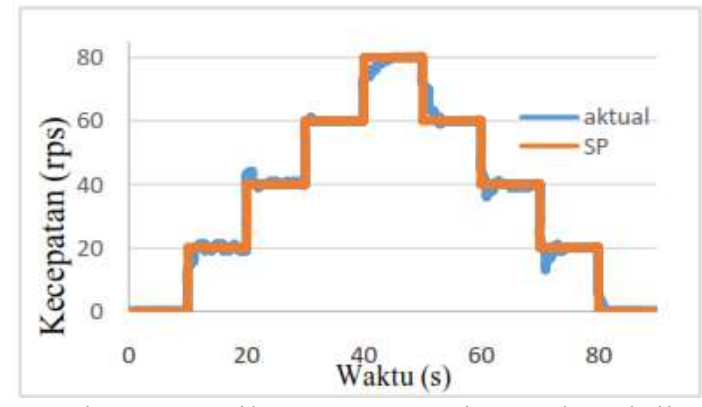

Gambar4. Hasil rancangan sistem kendali PID

Sistem perangkat lunak merupakan algoritma program sistem kendali PID yang dibuat dengan menggunakan CV Avr, 
kemudian didownload kedalam chip mikrokontroler dengan mneggunakan $A v r-$ Osp II.

\section{Hasil Pencarian Konstantan PID}

Berdasarkan hasil pencarian konstanta PID dengan metode internal kontrol diperoleh nilai-nilai sebagai berikut:

Tabel 1. Nilai konstata PID

\begin{tabular}{ccc}
\hline No & Konstanta & Nilai \\
\hline 1. & $\mathrm{~K}$ & 97,43241 \\
2. & $\mathrm{~T}$ & 0,024018 \\
3. & $\mathrm{D}$ & 0,03296 \\
4. & $\mathrm{Kp}$ & 0,259 \\
5. & $\mathrm{Ti}$ & 5,547 \\
6. & $\mathrm{Td}$ & 0,002 \\
\hline
\end{tabular}

Konstanta K, T dan d merupakan konstanta awal untuk mengetahui karakteristik motor dengan pemberian PWM. Konstanta tersebut kemudian digunakan untuk mendapatkan konstanta PID yaitu Kp, Ti dan $\mathrm{Td}$ dengan menggunakan metode internal control.

\section{Hasil uji fungsional kendali PID}

Data kecepatan yang telah direkam pada 9 set point yaitu 0,20,40,60,80,60,40, 20,0, dengan waktu perekaman 10 detik setiap set point, digambarkan dengan grafik respon

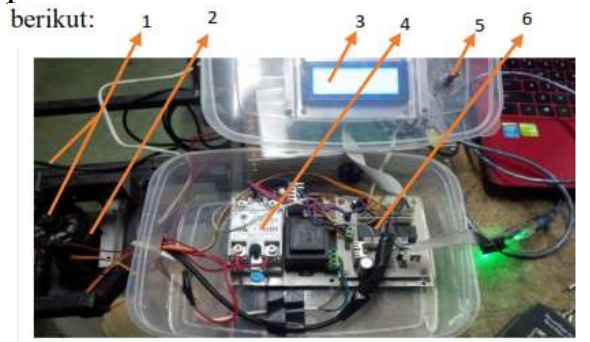

Gambar 5. Respon Kecepatan pada set point tanpa beban

Keterangan:

1. Rotary Encoder

2. Motor DC

3. LCD

4. Driver SSR

5. Potensiometer

6. Mikrokontroler
Dari Gambar 5 dapat dilihat bahwa respon sitem kendali dapat mengikuti set point yang diberikan pada kondisi naik maupun kondisi turun.

\section{Kecepatan Putar As Motor dalam Satuan RPM}

Motor DC yang digunakan adalah motor gearbox.Kecepatan putarpada as pemutar beban lebih kecil dari pada as untuk sensor kecepatan. Maka dari itu dilakukan pembacaan kecepatan putar pada as pemutar beban untuk membandingkan kecepatan pada kedua as motor. Berikut ini hasil pembacaan RPM pada as pemutar beban dan as untuk sensor kecepatan menggunakan Tacho meter:

Tabel 2. Kecepatan putar motor pada as sensor kecepatan dengan as pemutar beban

\begin{tabular}{ccc}
\hline $\begin{array}{c}\text { Set point } \\
\text { (RPS) }\end{array}$ & $\begin{array}{c}\text { As untuk } \\
\text { Sensor } \\
\text { (RPM) }\end{array}$ & $\begin{array}{c}\text { As pemutar } \\
\text { Beban (RPM) }\end{array}$ \\
\hline 20 & 1200 & 62 \\
40 & 2400 & 130 \\
60 & 3600 & 190 \\
80 & 4800 & 252 \\
\hline
\end{tabular}

Berdasarkan Tabel 2 perbandingan kecepatan antara as untuk sensor kecepatan dan as pemutar beban yaitu 20:1. Jika pembacaan as untuk sensor kecepatan dalam satu putaran 20 RPM maka kecepatan putar pada as pemutar beban 1 RPM.

Penggunaan satuan rps dalam semua pengolahan data, dilakukan untuk mempermudah pengolahan data kecepatan pada mikrokontroler, karena mikrokontroler yang digunakan terbatas yaitu 8 bit.

\section{Kinerja kontrol dengan beban Adonan roti}

Pengujian dengan menggunakan bahan adonan roti bertujuan untuk melihat kecepatan motor dengan menggunakan bahan yang memiliki torsi yang besar dengan jumlah bahan yang sedikit. Beban pertama dengan menggunakan $1000 \mathrm{~g}$ terigu, air $400 \mathrm{~mL}$, margarin $300 \mathrm{~g}$, pengembang $150 \mathrm{~g}$ (Bogasari,1989) dan 
bahan kedua mengunakan terigu $1,5 \mathrm{~kg}$ dan bahan campuran roti lainnya sesuai dengan komposisi Bogasari (1989).

1. Respon sistem dengan torsi $1,15 \mathrm{Nm}$ Untuk melihat kelebihanmenggunakan sistem kendali PID, maka dilakukan pengukuran kecepatan tanpa sistem kendali dan dengan sistem kendali PID untuk melihat perbedaan kedua sistem. Respon sistem tanpa kendali PID diperlihatkan dari gambar berikut:

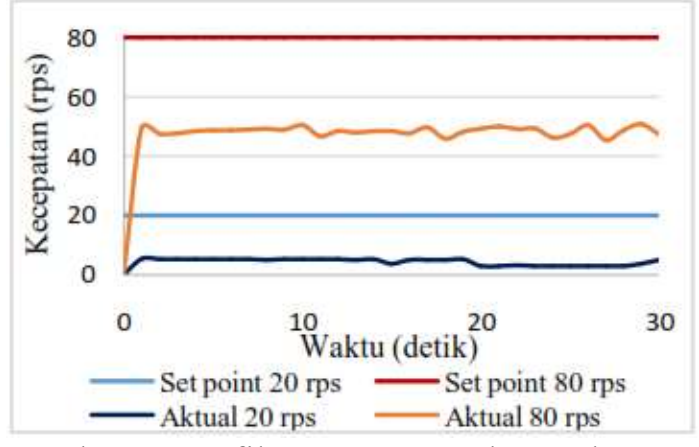

Gambar 6. Grafik respon tanpa kontrol PID

Berdasarkan Gambar 6 respon kecepatan motor tanpa menggunakan kontrol PID, tidak dapat mencapai set point jika telah diberikan beban. Set point rendah ataupun set point tinggi akan mengalami penurunan. Berikut ini karekteristik respon sistem tanpa kontrol disajikan dalam Tabel 3:

Tabel 3 Respon sistem tanpa kontrol

\begin{tabular}{cccc}
\hline $\begin{array}{c}\text { Set Point } \\
(\mathbf{r p s})\end{array}$ & $\begin{array}{c}\text { Settling } \\
\text { time } \text { (detik) }\end{array}$ & Overshoot $(\%)$ & $\begin{array}{c}\text { Ess } \\
(\%)\end{array}$ \\
\hline $\mathbf{2 0}$ & - & - & 77,59 \\
$\mathbf{4 0}$ & - & - & 70,07 \\
$\mathbf{6 0}$ & - & - & 44 \\
$\mathbf{8 0}$ & - & - & 39,96 \\
\hline
\end{tabular}

Pada Tabel 3 Error steady state yang terjadi sangat besar yaitu pada kecepatan rendah mencapai $70 \%$ sedangkan pada kecepatan tinggi mencapai $40 \%$. Tidak tercapainya set point menyebabkan nilai Settling time dan overshoot tidak ada.

Kecepatan putar aktual motor tidak tercapai karena tidak adanya sistem yang dapat memberi tegangan untuk menambah kecepatan motor. Akibat dari penurunan tegangan pada motor maka akan menyebabkan arus menjadi besar. Arus yang besar dapat membuat motor cepat panas dan mengurangi umur kerja dari motor yang digunakan. Untuk mencegah hal tersebut maka pengontrolan kecepatan putar motor pada mesin pengaduk dilakukan. Berikut ini respon sistem dengan menggunakan kendali PID, dapat dilihat dari Gambar 7.

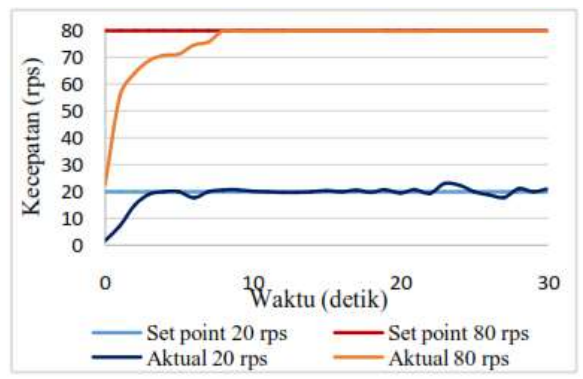

Gambar 7. Grafik respon dengan kontrol PID

Berdasarkan Gambar 7 respon sistem memperlihatkan kecepatan putar motor DC pada mesin pengaduk dapat mengikuti set point yang diberikan baik pada kecepatan rendah sampai pada kecepatan tinggi. Berikut ini karakteristik respon sistem kendali PID diperlihatkan pada Tabel 4.

Tabel 4. Respon sistem dengan kontrol PID

\begin{tabular}{cccc}
\hline $\begin{array}{c}\text { Set Point } \\
\text { (rps) }\end{array}$ & $\begin{array}{c}\text { Settling time } \\
\text { (detik) }\end{array}$ & Overshoot(\%) & $\begin{array}{c}\text { Ess } \\
\text { (\%) }\end{array}$ \\
\hline $\mathbf{2 0}$ & 3,2 & 5 & 0,51 \\
$\mathbf{4 0}$ & 4,0 & 7,6 & 0,03 \\
$\mathbf{6 0}$ & 5,8 & 0 & 0,20 \\
$\mathbf{8 0}$ & 7,8 & 0 & 0,17 \\
\hline
\end{tabular}

Berdasarkan Tabel 4, waktu yang dibutuhkan sistem untuk mencapai kecepatan yang diinginkan kurang dari 10 detik. Pada kecepatan rendah terjadi overshoot sedangkan pada kecepatan tinggi tidak terjadi. Hal ini terjadi karena sistem bekerja cepat dalam menyuplai tegangan kepada motor untuk mencapai set point, sehingga pada set point kecepatan rendah terjadi lewatan karena merupakan range awal. Overshoot yang terjadi masih dianggap baik karena tidak memberikan pengaruh berarti terhadap bahan yang diaduk. 
Penerapan sistem kendali pada motor dapat menurunkan nilai kesalahan kecepatan putar yang terjadi. Penurunan kesalahan menjadi 0 menunjukkan bahwa sistem dapat bekerja sesuai dengan set point. Dari empat variasi kecepatan yang diberikan (20, 40, 60 dan $80 \mathrm{rps})$, terhadap kecepatan aktual yang terjadi pada motor,diperoleh pengaruh yang linear antara keduanya (set point dan kecepatan aktual). Nilai regresi sebesar 0,9997 menunjukkan bahwa kecepatan motor telah mencapai set point yang diberikan.

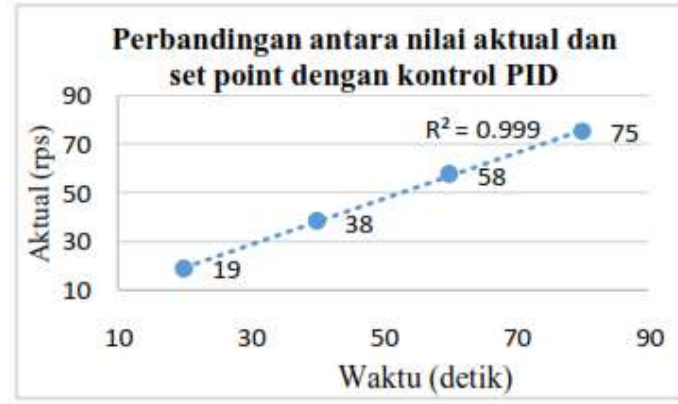

Gambar 8. Perbandingan set point dan kecepatan aktual dengan sistem kontrol PID

\section{Respon sistem dengan torsi $1,54 \mathrm{Nm}$}

Perlakuan terhadap motor tanpa kontrol PID dan dengan menggunakan kontrol PID dapat dilihat dari gambar berikut:

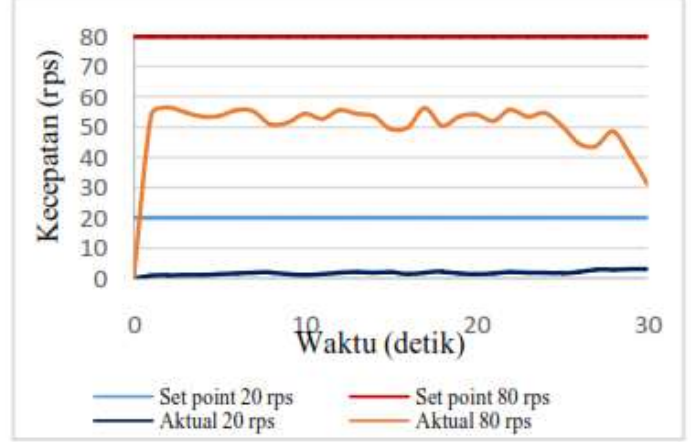

Gambar 9. Grafik respon tanpa kontrol PID

Berdasarkan Gambar 9 respon sistem tanpa mengunakan kontrol PID memperlihatkan bahwa kecepatan putar tidak dapat mengikuti set point yang diberikan. Semakin besar torsi beban yang diberikan membuat kecepatan motor semakin jauh dari kecepatan yang diinginkan (set point). Berdasarkan hal tersebut maka dapat dilihat karakteristik respon sistem tanpa menggunakan kontrol PID pada tabel berikut:

Tabel 5. Respon sistem tanpa kontrol

\begin{tabular}{cccc}
\hline $\begin{array}{c}\text { Set Poin } \\
(\mathbf{r p s})\end{array}$ & $\begin{array}{c}\text { Settling time } \\
\text { (detik) }\end{array}$ & Overshoot(\%) & Ess (\%) \\
\hline 20 & - & - & 90,71 \\
40 & - & - & 83,32 \\
60 & - & - & 65,56 \\
80 & - & - & 35,90 \\
\hline
\end{tabular}

Berdasarkan Tabel 5 nilai kesalahan (error steady state) pada kecepatan rendah mencapai $90 \%$ sedangkan pada kecepatan tinggi mencapai $35 \%$. Nilai tersebut sangat besar sehingga penggunaaan motor tanpa kendali sangat merugikan apalagi dengan menggunakan bahan dengan torsi yang besar. Hal ini dapat membuat proses pengadukan lebih lama dan menurunkan mutu bahan yang diaduk.

Sedangkan dengan menggunakan kendali kecepatan putar motor, respon sistem dapat dilihatdari grafik respon sistem berikut:

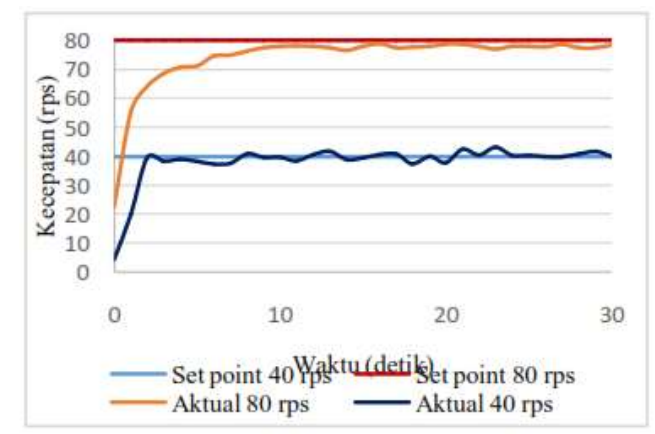

Gambar 10. Grafik respon sistem kontrol PID

Berdasarkan Gambar 10 respon sistem menunjukkan kecepatan motor dapat mengikuti set point yang diberikan. Pada kecepatan rendah respon memperlihatkan adanya osilasi pada saat kondisi steady state. Osilasi ini terjadi karena adanya pengaruh beban yang berat. Sedangkan pada set point tinggi kecepatan aktual motor masih berada sedikit dibawah kecepatan yang diinginkan. Penurunan kecepatan aktual pada kecepatan 80 rps 
masih dapat dinggap baik karena persen kesalahannya masih berada pada batas persentasi mutlak yang diizinkan yaitu $2 \%$ atau 5\% (Ogata, 1997). Berikut ini karakteristik respon sistem kendali PID pada torsi beban 1,54 Nm.

Tabel 6. Respon sistem dengan kontrol PID

\begin{tabular}{cccc}
\hline $\begin{array}{c}\text { Set Point } \\
\text { (rps) }\end{array}$ & $\begin{array}{c}\text { Settling } \\
\text { time } \text { (detik) }\end{array}$ & $\begin{array}{c}\text { Overshoot } \\
(\%)\end{array}$ & Ess (\%) \\
\hline 20 & 5,8 & 15 & 0,687 \\
40 & 7,0 & 0 & 0,263 \\
60 & 7,6 & 0 & 0,261 \\
80 & 16 & 0 & 0,266 \\
\hline
\end{tabular}

Respon sistem kontrol PID memperlihatkan bahwa waktu yang diperlukan untuk mencapai set point kurang dari 10 detik pada kecepatan 20 60 rps. Sedangkan pada set point 80 rps waktu yang diperlukan lebih lama yaitu 16 detik. Nilai overshoot masih dianggap baik karena tidak membuat propellerberputar tanpa kendali. Hasil dari sistem kendali kecepatan putar motor pada mesin pengaduk memperlihatkan hubungan yang linear antara set point dengan kecepatan aktual motor yang ditandai dengan nilai regresi yang mencapai 1 yaitu 0,9991 . Walaupun sistem mengalami osilasi akantetapi osilasi yang terjadi masih berada pada persentasi mutlak yang diizinkan yaitu 2-5\% (Ogata, 1997). Dalam proses pengadukan, sistem tidak dituntut pada kestabilan tinggi.

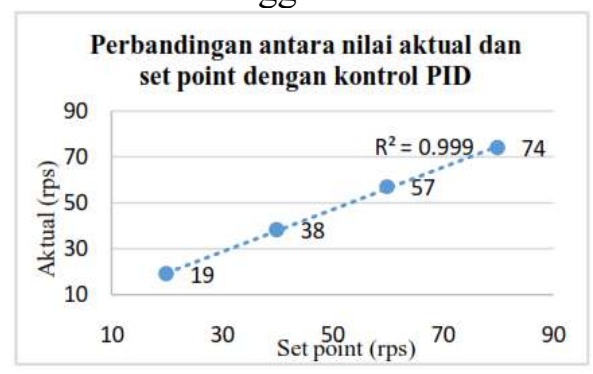

Gambar 11. Perbandingan antara set point dengan kecepatan aktual

\section{Kinerja kontrol dengan beban kedelai}

Bahan kedelai yang diaduk bertujuan untuk melihat kecepatan putar motor saat melakukan pengadukan dengan beban kedelai. Pada awalnya kedelai direndam selam 3-4 jam untuk mempermudah pengupasan kulit. Bahan pertama yang diaduk yaitu kedelai $5 \mathrm{~kg}$ dengan 5 liter air. Bahan kedua $10 \mathrm{~kg}$ kedelai dengan 10 liter air. Hasil pengujian yang telah dilakukan yaitu:

1. Respon sistem dengan torsi $0,41 \mathrm{Nm}$

Pengadukan dengan menggunakan beban dilakukan dengan membuat dua perlakukan yaitu pengadukan tanpa kontrol dan dengan menggunakan kontrol. Respon kecepatan putar motor dengan perlakuan tanpa kontrol dapat dilihat dari gambar berikut:

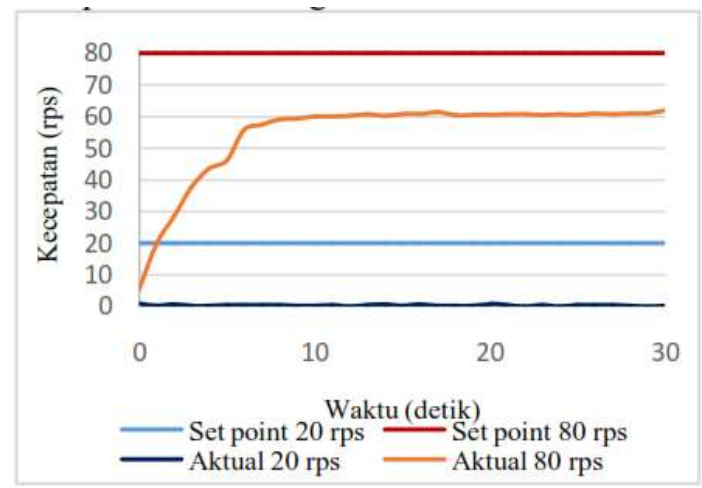

Gambar 12. Grafik respon tanpa kontrol PID

Tabel 7. Respon sistem tanpa kontrol

\begin{tabular}{cccc}
\hline $\begin{array}{c}\text { Set Point } \\
\text { (rps) }\end{array}$ & $\begin{array}{c}\text { Settling } \\
\text { time (detik) }\end{array}$ & Overshoot(\%) & Ess (\%) \\
\hline 20 & - & - & 98,71 \\
40 & - & - & 16,59 \\
60 & - & - & 21,05 \\
80 & - & - & 27,64 \\
\hline
\end{tabular}

Berdasarkan Gambar 12, respon sistem menunjukkan bahwa kecepatan aktual motor tidak dapat mengikuti set point yang diberikan baik pada kecepatan rendah maupun kecepatan tinggi. Kesalahan keadaan tunak juga sangat besar pada kecepatan rendah. Hal ini seharusnya tidak terjadi karena beban yang diaduk masih berada dibawah torsi motor (torsi motor $7 \mathrm{Nm}$ ), akan tetapi karena sistem yang bekerja merupakan sistem lup terbuka dimana tidak ada yang menginformasikan nilai kecepatan motor dan tidak ada sistem yang memperbaiki 
kesalahan yang terjadi maka motor akan terus berputar pada kondisi tersebut.

Sedangkan respon kecepatan putar motor dengan perlakuan menggunakan sistem kendali PID dapat dilihat dari gambar berikut:

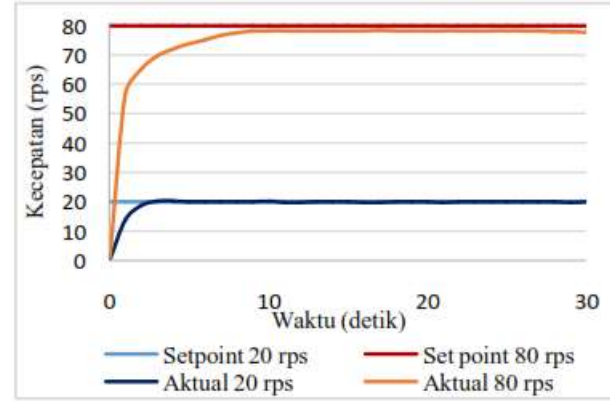

Gambar 13. Grafik respon dengan kontrol PID

Tabel 8. Respon sistem dengan kontrol

\begin{tabular}{cccc}
\hline $\begin{array}{c}\text { Set Point } \\
\text { (rps) }\end{array}$ & $\begin{array}{c}\text { Settling time } \\
\text { (detik) }\end{array}$ & Overshoot(\%) & Ess (\%) \\
\hline 20 & 3,0 & 0 & 0,21 \\
40 & 4,0 & 0 & 0,30 \\
60 & 5,6 & 0 & 0,22 \\
80 & 8,2 & 0 & 2,1 \\
\hline
\end{tabular}

Respon sistem kendali menunjukkan bahwa kecepatan dapat mengikuti dan stabil pada set point yang diberikan. Hal ini dapat dilihat dari nilai regresi antara set point dengan kecepatan aktual motor yang hampir mencapai 1.

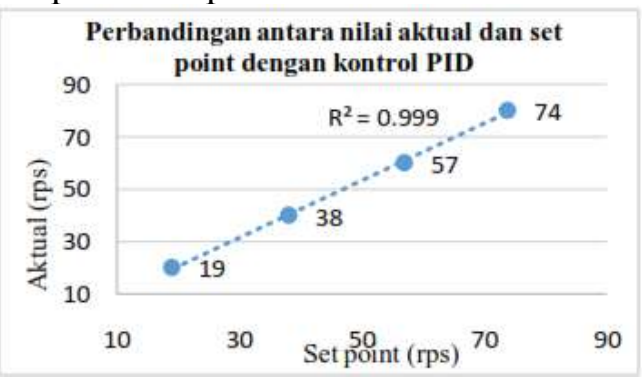

Gambar 14. Perbandingan set point dengan nilai kecepatan aktual

\section{Respon sistem dengan torsi $1,78 \mathrm{Nm}$} Perlakukan dengan torsi beban kedua dilakukan dengan menggunakan 2 pengujian yaitu pengujian tanpa kontrol dan pengujian dengan mengunakan kontrol PID. Respon kecepatan mesin pengaduk tanpa kontrol yaitu:

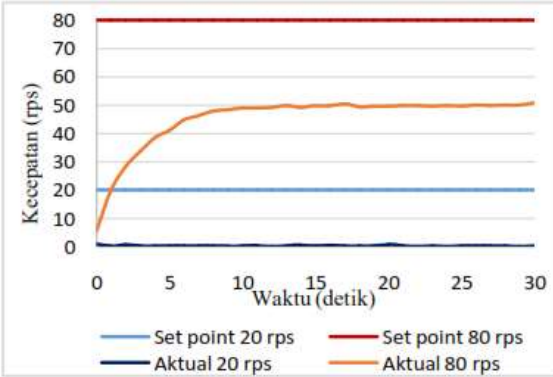

Gambar 15 . Respon sistem tanpa kontrol

Tabel 9. Respon sistem tanpa kontrol

\begin{tabular}{cccc}
\hline $\begin{array}{c}\text { Set Point } \\
\text { (rps) }\end{array}$ & $\begin{array}{c}\text { Settling } \\
\text { time (detik) }\end{array}$ & Overshoot(\%) & Ess (\%) \\
\hline 20 & - & - & 98,11 \\
40 & - & - & 40,23 \\
60 & - & - & 34,98 \\
80 & - & - & 40,37 \\
\hline
\end{tabular}

Berdasarkan Gambar 15 respon sitem memperlihatkan bahwa kesalahan keadaan tunak atau error steady state sangat besar, yaitu pada kecepatan rendah mencapai 98\% sedangkan pada kecepatan tinggi $40 \%$. Persentasi kesalahan yang besar membuktikan bahwa kecepatan aktual tidak dapat mencapai set point yang diberikan. Sedangkan respon kecepatan mesin pengaduk dengan menggunakan sistem kontrol PID yaitu:

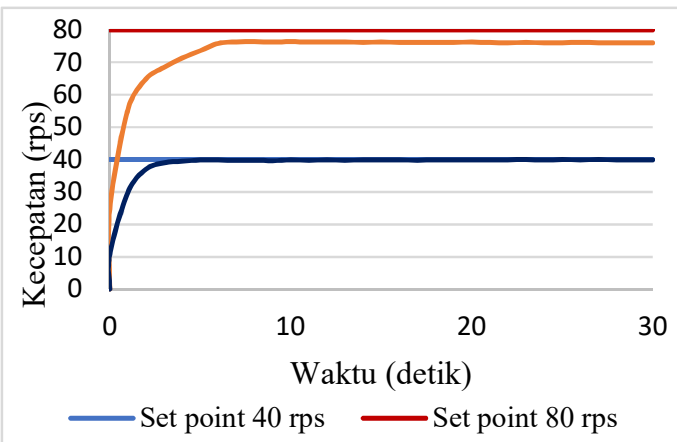

Gambar 16. Grafik respon dengan kontrol PID

Tabel 10. Respon sistem dengan kontrol PID

\begin{tabular}{cccc}
\hline $\begin{array}{c}\text { Set Point } \\
\text { (rps) }\end{array}$ & $\begin{array}{c}\text { Settling } \\
\text { time (detik) }\end{array}$ & Overshoot(\%) & Ess (\%) \\
\hline 20 & 2,0 & 5 & 0,33 \\
40 & 3,8 & 0 & 0,33 \\
60 & 8,2 & 0 & 0,24 \\
80 & 8,8 & 0 & 4,76 \\
\hline
\end{tabular}


Berdasarkan hasil pengujian dengan menggunakan beban kedelai, kecepatan putar motor tanpa ada sistem kendali tidak dapat mencapai set point yang diinginkan, sedangkan dengan menggunakan sistem kendali kecepatan dapat dicapai dengan waktu yang singkat dengan kondisi yang stabil. Tidak terjadi overshoot dan kesalahan keadaan tunak atau error steady state masih berada pada nilai persentasi mutlak yang diizinkan dalam suatu sistem kontrol yaitu 2-5\% (Ogata,1997) dan hubungan antara nilai aktual dengan set point memperlihatkan adanya kesamaan nilai yang ditandai dengan nilai regresi sebesar 0,9978.

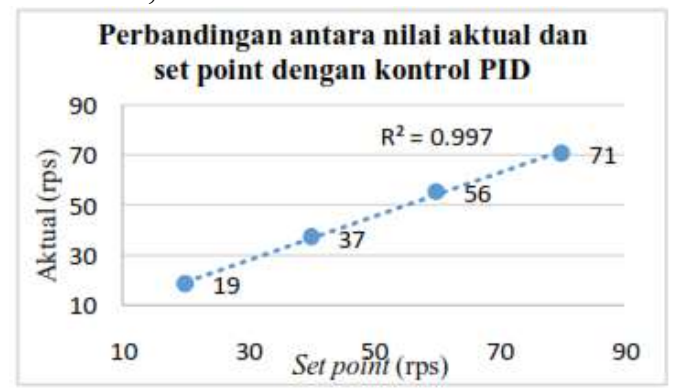

Gambar 17. Perbandingan antara set point dengan kecepatan aktual motor

Berdasarkan pada hasil uji kinerja mesin pengaduk pada berbagai torsi beban memperlihatkan bahwa kontrol PID mampu mengendalikan kecepatan putar motor sesuai dengan kecepatan yang diinginkan. Keuntungan sistem kendali pada mesin pengaduk yaitu dapat memberikan kecepatan yang diinginkan, mempercepat proses pengadukan, membuat mutu bahan pengadukan lebih baik dan membuat motor tahan lama.

\section{KESIMPULAN DAN SARAN}

\section{Kesimpulan}

Berdasarkan hasil penelitian yang dilakukan dapat ditarik kesimpulan sebagai berikut:

1. Telah dihasilkan sistem kendali kecepatan putar motor DC pada mesin pengaduk dengan kinerja yang baik.

Jurnal AgriTechno (Vol. 11, No.1, April 2018)
2. Respon sistem dari semua set point kecepatan yang diinginkan sudah bekerja dengan baik, yang ditandai dengan nilai kesalahan keadaan tunak yang tidak melebihi $2 \%$ atau $5 \%$, nilai regresi yang mencapai 1 dan bahan tidak tumpah dari wadah.

\section{Saran}

Saran pada penelitian ini yaiotu perlu dilakukan perubahan pada alat untuk menunjang kegiatan pengadukan dengan menggunakan bahan pada torsi yang lebih besar yaitu wadah penampung bahan dan bodi mesin dibuat menyatu. Selain itu perlu dilakukan pengujian lebih lanjut terhadap bahan - bahan pertanian lain untuk mengetahui kinerja dari mesin pengaduk selain dari adonan dan kedelai.

\section{DAFTAR PUSTAKA}

Afifah, Meita. 2013. Dasar Teori Mixing.https://www.scribd.com/doc/1 84122963/Dasar-Teori-Mixing. Diakses pada tangal 31 Januari 2018.

Ahter Sirait, Willy. 2013. Perancangan dan simulasi mesin pengaduk kapasitas 6,9 liter putaran $280 \mathrm{rpm}$ menggunakan ansys fluent 14,0 dan pengujian. Medan: Universitas Sumatera Utara.

Anonim ${ }^{1}$, 2015. Pengetahuan Dasar penggunaan Timer Counter Microkontroller AVR.https://pckontro 1.wordpress.com/2011/08/14/pengeta huan-dasar-penggunaan-timercounter-microkontroller-avr/.Diakses pada tanggal 13 Mei 2017

Asih Priyati. 2016. Pengaruh Kecepatan Putar Pengadukan Adonan Terhadap Sifat Fisik Roti. Jurnal ilmiah rekayasa pertanian dan biosistem. Vol.4 No. 1 Universitas Mataram

Bregas., Sembodo., Noorlyta, Ardiena., dan Erika L M, Nur. 2010. Pengaruh Keceptan Putar Pengaduk Proses Pemecahan Emulsi Santan Buah Kelapa Menjadi Virgin Voconut Oil 
(VCO). Equilibrium Vol.9 No. 1. Halaman: 17 - 22. Surakarta: Universitas sebelas Maret Surakarta.

Endaryono. (2014). Microkontroller ATmega32.http://sir.stikom.edu/999/5 /BAB_II.pdf.Diakses pada tanggal 15 Mei 2017.

Fathur R. pepen. 2016. Pemodelan dan Simulasi Kestabilan Respon Transien Motor DC Magnet permanen Menggunakan Graphical User Interface (GUI) pada Simulink Matlab 2008R Versi 7.7.0. Universitas Suryadarma.

Hermawan, Indra. 2015. Studi experimental pengaruh variasi temperature dan putaran terhadap sifat mekanik campuran polypropylene, polyetylen dan fiber glass menggunakan mesin pengaduk buatan sendiri. Medan: Universitas Sumatera utara.

Ogata, Katsuhiko. 1997. Teknik Kontrol Automatik (sistem pengaturan) Jilid 1. Erlangga: Jakarta.

Pinem, Andreas. 2008. Pengaturan Kecepatan Motor Penguatan Shunt dengan Integral Siklus Kontrol (Aplikasi pada Laboratorium Konversi Energy Listrik FT-USU). Medan: Universitas sumatera Utara.

Rahman W, Abdul., Mulyaningsih, Nani., Salahuddin, Xander. 2017. Analisis Mesin Mixer HorizontalDengan Variasi Putaran dan Waktu Pengadukan. Universias Tidar: Magelang

Reokmono dan Biyanto, Totok R. 2017. Pembuatan Alat Tunning pengendali PID.http://personal.its.ac.id.pdf. diakses pada tanggal 31 Mei 2017.

Sapsal, M Tahir. 2012. Desain dan Pengujian Prototipe Mesin Pemupuk Butiran Laju Variabel Empat Baris untuk Pertanian Presisi. Institut Pertanian Bogor: Bogor.
Wawolumaja, R. 2013. Bab. 3 Sistem Pengaturan Otomatis (Level 2 Sistem Otomasi). Universitas Kristen Maranatha: Bandung.

Zilkha, D., \& Ya'umar. (2012). Rancang Bangun Sistem Pengendali Kecepatan Motor DC dengan Menggunakan Metode Pengendali PID pada Mobil Listrik. http://digilib.its.ac.id.pdf. Diakses pada tanggal 13 Mei 2017. 